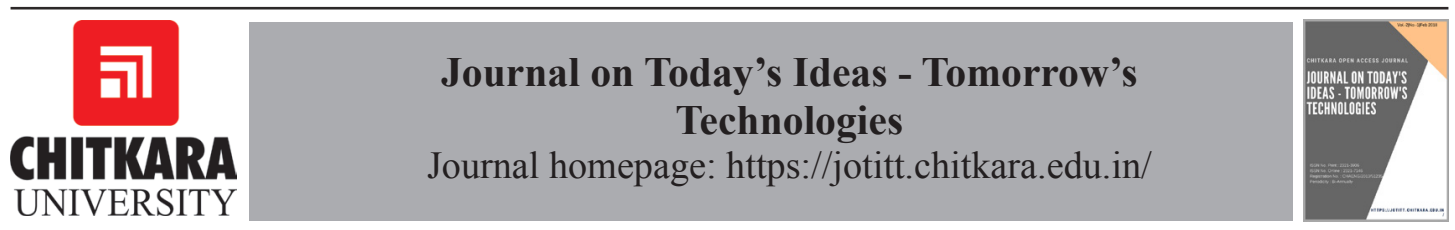

\title{
Flashover Characteristics Performance Assessment under Contamination Possessions on the Surface of Porcelain Insulators
}

\author{
Rahul Soni*, Mihir Bhatt \\ Chandubhai S. Patel Institute of Technology, Charusat University, Gujarat, India. \\ *Email: rahulsoni.ee@charusat.ac.in
}

ARTICLE INFORMATION

DOI: $10.15415 /$ jotitt.2018.61005

Keywords: Porcelain Insulators, Dust, $\mathrm{NaCl}$, Moisture, Contamination, Flashover, Breakdown Voltage

\begin{abstract}
This paper presents the experimental outcomes regard to the flashover performance of pin, shackle and disc insulators under contaminated conditions. For making contaminated surface various samples are made like salt, dust, industry pollution and miscellaneous foreign particles of wet and dry conditions as per IEC testing techniques. Moreover, each insulator has been tested under above mentioned conditions. For each insulator its breakdown voltages were measured. After doing performance analysis of different insulators under contaminated condition measurement of breakdown voltages are done with incorporation of real field application of insulators and making analogy with various regions of India.
\end{abstract}

\section{Introduction}

Due to the demand of electric power is substantially improved in recent days. Each and every electrical equipment must be designed, commissioned and tested for critical situations. To keep the system healthy and sound from transmission to distribution to consumer end continuous monitoring is required. For longer transmission system different insulators are used with different materials like porcelain, ceramic, glass. The performance of insulator under different contaminations was also studied [1]. As per the research it has been evaluated that various parts of country is having various pollutants that deposit on the surface of insulators [2]. Porcelain, ceramic, polymeric types insulators are also affected by $\mathrm{NaCL}$ and other foreign particles deposition and just due to that various flashover mechanisms have been observed under wet and dry conditions [3]. The insulators commence to fail due to mixture of air particles, water dew drops, salt and fog conditions under behavior of

The Author(s) 2018. This article is published with open access at www.chitkara.edu.in/publications. https://doi org//10.15415/ jotitt.2018.61005 | ISSN No.: 2321-3906 (Print) ISSN No.: 2321-7146 (Online) Registration No. : CHAENG/2013/51235 Periodicity: Bi-Annually 
environmental parameters [4]. If proper cleanliness is not maintained this pollutants try to degrades the quality of insulator and gradually life cycle of insulators [5]. Due to pollutants various treeing and tracking process is elongated throughout the surface of insulators and small sparks will be continued to make flashover on the specimen [6]. An experimental procedure helps to identify flashover characteristic because of contamination influence and degradation of heath index of insulation surface as well as on a longer run its properties [7-8]. Performance of insulator varies according to various environmental factors [9]. Not only the insulators that are used in transmission lines but also insulators used in traction applications are similarly affected by environmental parameters like wind, humidity etc. [10]. Polymeric type insulators were also commissioned and tested in japan and performance of insulators in terms of leakage currents were measured [11]. Due to failure of mixing with water it is having small values of currents and now due to aid of contamination high value of currents are measured [12]. Simple construction shows leakage current and breakdown voltage on the other hand complex construction depends upon various parameters like dimensions and design [13-14]. Outdoor insulators prone to external interventions and based on that its reliability is drastically reduced [15]. Such contamination effects are not severe in terms of residential areas unlikely hilly and farming regions [16].

At present days due to prompt demand of power supply more industries are progressed to reach that power demand and those zones are affected harshly by several contaminations. When this dust and other pollutant mixed with other wet and dry contaminant particles, as these pollutants are having contrary effects on life cycle of insulators and moreover it reduces the dielectric properties of insulators in many regions of India like many states nearby coastal areas. The left over part of the paper is prepared as follows: Breakdown Mechanism, Experimental Details, Results and Discussions and Conclusion.

\section{Insulator surface flashover propagation of polluted insulator}

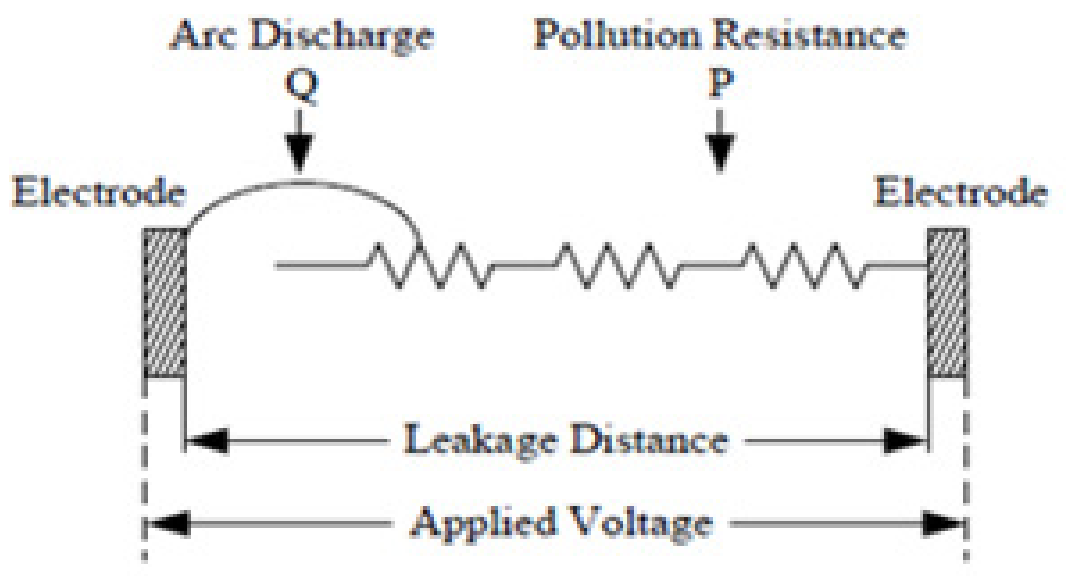

Figure 1: Obenaus model of polluted insulator [11]. 
When there is monsoon condition or due to any wet particles possessions on the surface of insulators, probabilities of flashover occurrence increase and due to leakage current possibilities of temperature rise will lead to evaporation of moisture contents that forms dry bands over it. Dry band tends to initiate where diameter is small as this region is having more leakage current density. The high surface resistance formed due to unclean surface, the high potential is developed across the dry regions. Successively initiation of arc will be taking place and due to that elongation of arc over the surface gradually lead towards the flashover mechanism. The arc will disseminate over the insulator's surface if the potential gradient of contaminated layer is more than gradient of arc.

By the time, the flashover takes place when the promulgated streamer bridges the whole insulator. The flashover elicits a power arc that fallouts in the interruption of electricity and may hurt the insulator momentarily or everlastingly, depending on the rigorousness of spark.

The flashover process of contaminated insulators can be described by confined flash in series with the resistance of the smog layer as shown in Fig. 1. So as to examine the flashover event, the characteristics of the confined flash and the shallow conductivity must be defined appropriately.

According to the experimental data, the V-I characteristics of arcs can be expressed as the discussed model is given as follow:

Earc $=$ AInarc

Where Iarc is the leakage current, A and n are arc constants.

The consistency and constancy of transmission and distribution overhead lines effectively diminishes due to rise in sparkover probability of insulators under contaminated environment. Deposition of such pollution enhances the surface conductivity that allows more leakage current to flow and thus reduces the voltage barring capacity [12].

\section{Breakdown mechanism in insulators}

The performance of the insulators installed on overhead transmission lines are greatly affected due to numerous pollutions such as natural, industrial or even mixed one. The adverse effect of deposited pollutant will reduce the voltage withstand capacity of line insulators [16,]. Under dry and clean environment, the polluted surface of an insulator has little effect on the development of surface gradient [11]. But the potential gradient across the surface becomes more than corona threshold when the surface becomes more conductive during moisturized conditions. The moisturized surface will allow more leakage current to flow and increases the temperature gradients at the regions of high current density. Gradually, the heat in these zones attains boiling point temperature and causes the evaporation of the water particles absorbed by the surface of an insulator [17].

The shape and dimensions of the insulators varies type to type and hence the dry areas. The utmost significant problems faced by transmission system are the unintentional sparkover of insulators and the difficulty observed during the insulation coordination process under polluted conditions. Due to complexity in shape and multifaceted nature of pollution, more research needs to be conducted to understand the behaviour of the insulators under polluted conditions as it causes long term power outages over a large area [2]. The past research has been conducted to understand the phenomena of growth of discharge and flashover propagation to predict the critical flashover voltage and current [4]. 


\section{Experimental details}

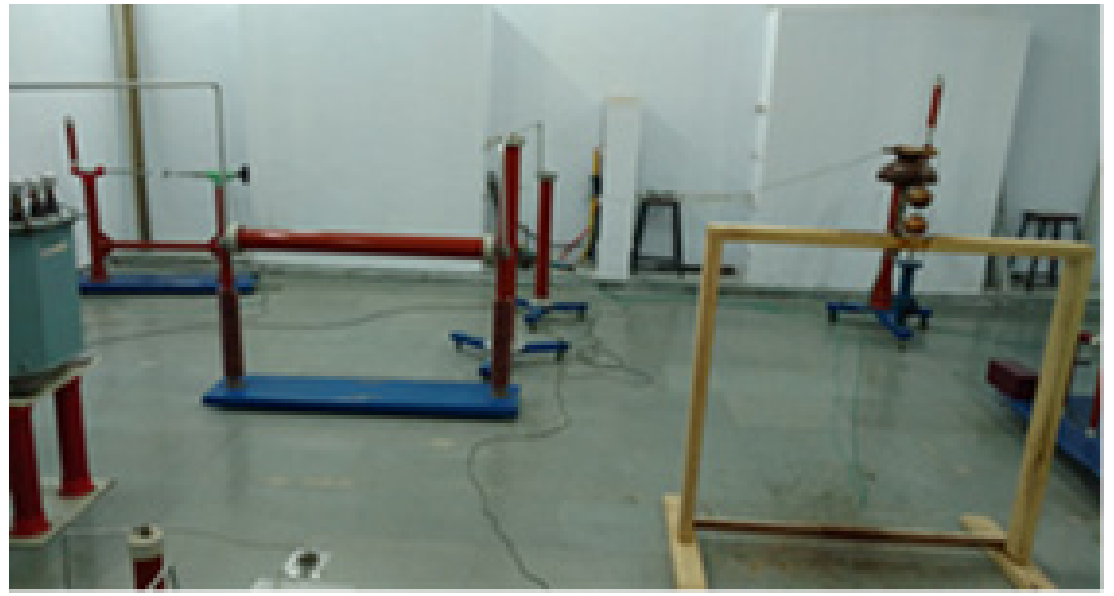

Figure 2: Laboratory experimental setup

The research work had been done in the High Voltage Engineering laboratory of Charotar University of Science and Technology. It includes series connections of transformer, rectifier, and filter and resistance divider circuits with incorporation of control panel.

The detail specifications of cascade transformer are as follows: rated capacity is 3 $\mathrm{kVA}$; available voltages as per unit are $100 \mathrm{kV}$. Schematic planning of research work has been introduced in shown Fig. 2. Each insulator was connected as per setup as well as according to IEC test techniques and specification. Voltages are applied test specimen and contaminated conditions are applied then flashover and breakdown voltages are identified and analysed as per connected in the system. An investigation has been done as per IEC standard and detail test specification [8-9].

\subsection{Test procedure for dust and salt deposition due to coastline area con- tamination on pin insulator}

Prior to carry out the test setup the insulators were kept and neat cotton cloth piece to remove foreign particles, impurities and other lubricants [3]. Afterwards cleaning, the insulators then were dehydrated certainly for minutes. Then for the healthy samples the maximum breakdown voltages and flashover conditions were observed and measured. The standard deposition method was incorporated to make the insulator in unhealthy condition. As far as the coast line area was concerned salt proportion had been identified as 50 grams of salinity per $250 \mathrm{ml}$ of liquid.

In this work salinity contained low and high concentration was scattered and deposited on the surface of insulators during experiment. For dust pollution test, 50 grams of dust was liquefied in $250 \mathrm{ml}$ of water and sprayed on the samples.

To obtain thin layer over the surface of insulators, the pollutants sprayed over the surface were dried out by some external means. This process will allow uniform distribution of mixture and entirely covers the insulator's surface. In this study, it was detected that, the thin layers of dust particles with salt mixture moisture droplets are deposited on the surface of insulator. This 
phenomenon happened due to the external environmental factors and deposition of these particles on circumference of the por-

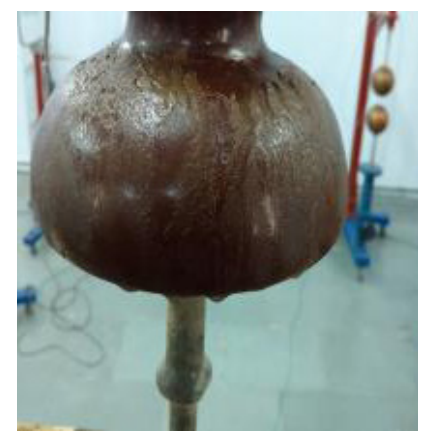

Figure 3: Appearance of dust and salt particles with wet condition on the surface of pin insulator

\subsection{Test procedure for dust contamination deposition due to industrial as well as surrounding pollutants on disc insulator}

Prior to carry out the test setup the insulators were kept and neat cotton cloth piece to remove foreign particles, impurities and other lubricants [3]. Afterwards cleaning, the insulators then were dehydrated certainly for minutes. Then for the healthy samples the maximum breakdown voltages and flashover conditions were observed and measured. The standard deposition method was incorporated to make the insulator in unhealthy condition. In this work a various industrial celain insulator. Fig. 3 represents mixture of salt and dust deposition formation on the test specimen.

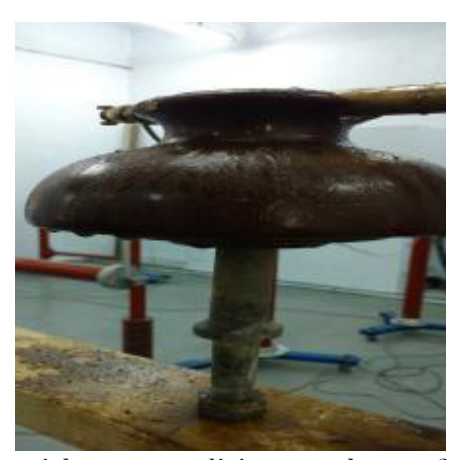

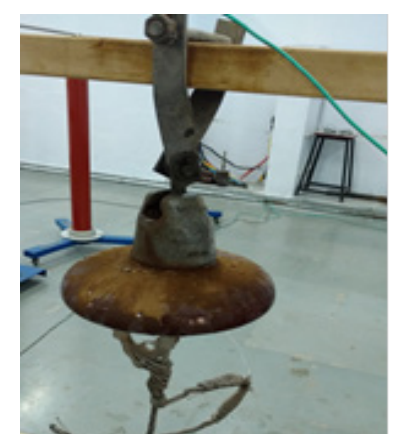
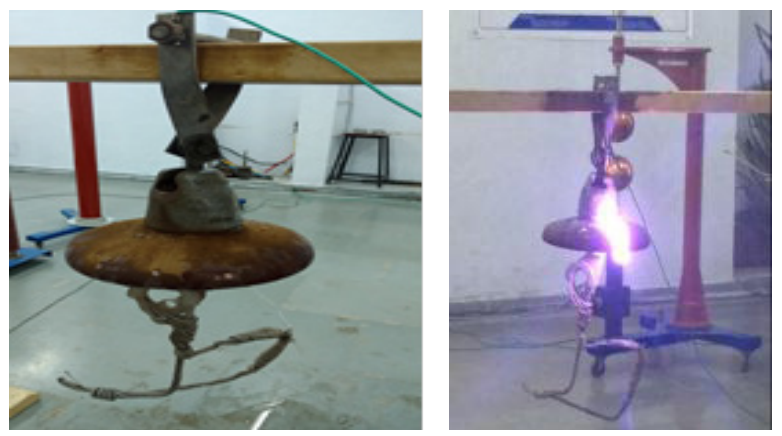

Figure 4: Appearance of pollutant composition with wet and dry condition on the surface of disc insulator with flashover

ISSN No.: 232 1-3906 (Print) ISSN No.: 2321-7146 (Online) Registration No.: CHAENG/2013/51235 Periodicity: Bi-Annually 
In this experiment, it was observed that, the thin layers of dust particles with moisture droplets are deposited on the surface of insulator. It took place due to environmental parameters and atmosphere of industry that gradually degrades the dielectric properties of insulator.

Moreover, in the result analysis the breakdown voltages are drastically reduced and probability of flashover also increases due to contamination effect on the periphery of insulator. Fig. 4 represents solvent of dust particles with dry and wet deposition formation on the test specimen respectively.

\subsection{Test procedure for miscellaneous contamination deposition due to manufacturing pollutants}

Prior to carry out the test setup the insulators were kept and neat cotton cloth piece to remove foreign particles, impurities and oth-

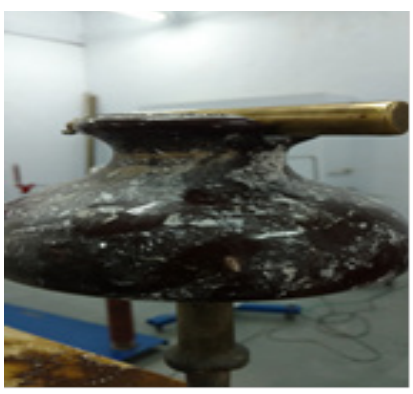

er lubricants [3]. Afterwards cleaning, the insulators then were dehydrated certainly for minutes. Then for the healthy samples the maximum breakdown voltages and flashover conditions were observed and measured. The standard deposition method was incorporated to make the insulator in unhealthy condition.

In this work a various industrial contaminants like lime stone particles, cement particles along with some chemical particles artificially were scattered on the surface of insulators under Industrial contamination assessment. For dust, cement and lime stone pollution test 50 grams of mixture of above mentioned contaminants were dissolved in $250 \mathrm{ml}$ of water and sprayed on the samples. Fig. 5 and Fig. 6 represent solvent of dust particles with dry and wet deposition formation on the test specimen respectively.

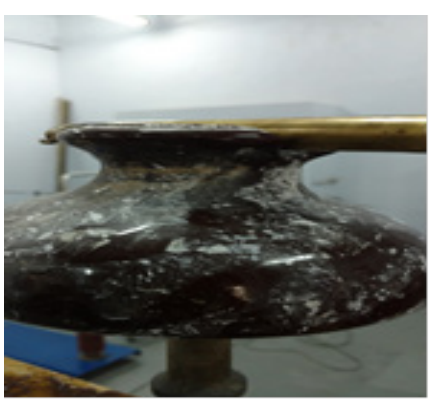

Figure 5: Appearance of pollutant composition with wet and dry condition on the surface of pin insulator
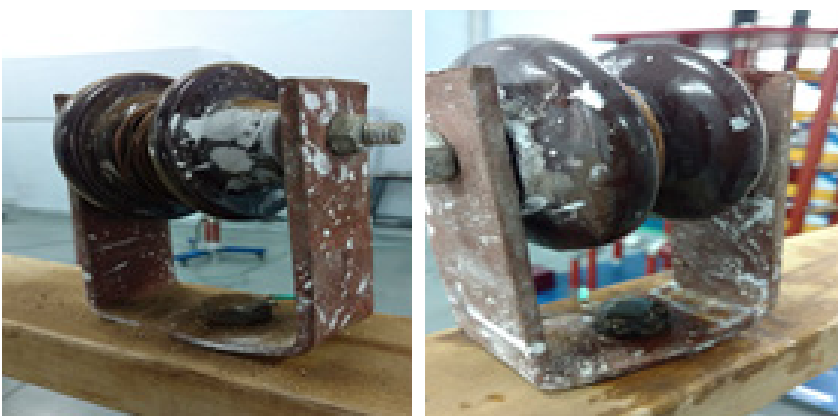

Figure 6: Appearance of pollutant composition with wet and dry condition on the surface of Shackle insulator

ISSN No.: 232 1-3906 (Print) ISSN No.: 2321-7146 (Online) Registration No.: CHAENG/2013/51235 Periodicity: Bi-Annually 
Moreover, from each investigation we have seen that due to this various contamination layers there was drastic change was observed in terms of breakdown voltage characteristics as these pollutants help to create arc in wet condition more compare to dry condition and eventually the flash over phenomenon was also observed for pin type, Disc type and Shackle Type Insulator.

\section{Electric field analysis of insula- tor under contamination using COMSOL multiphysics}

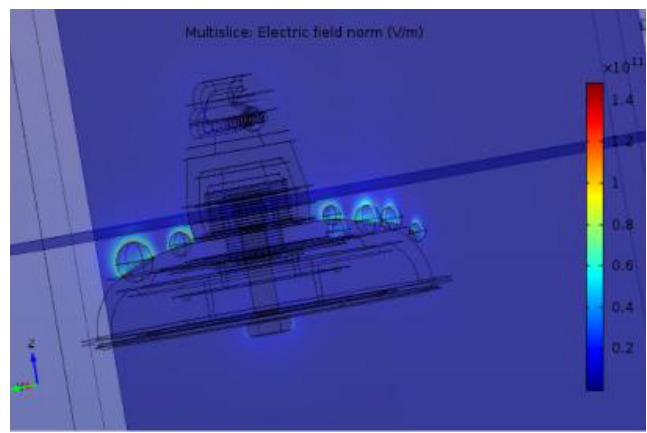

When insulator is new or properly maintained probabilities of field stress and flashover is less. However, contaminants like water droplets, dust, $\mathrm{NaCl}$ and industry pollutants were scrattered on disc surface, conductive path forms on the surface of disc due to which leakage current flows, also the electric stress increased which result in to lesser breakdown voltage, also as the conductivity increases the propagation of streamer under all the contaminant condition becomes more uniform and voltage required for flash over decreases as shown in Fig. 7.

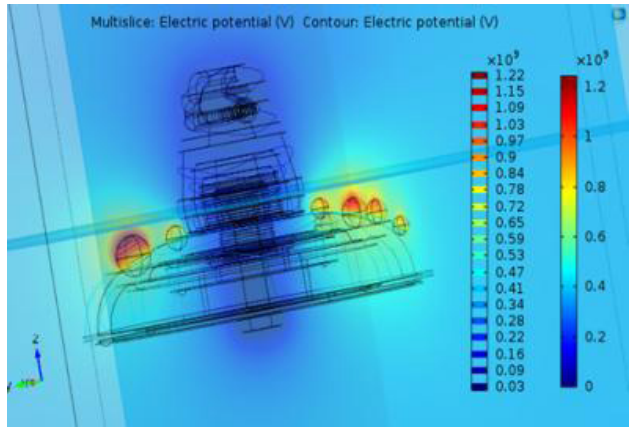

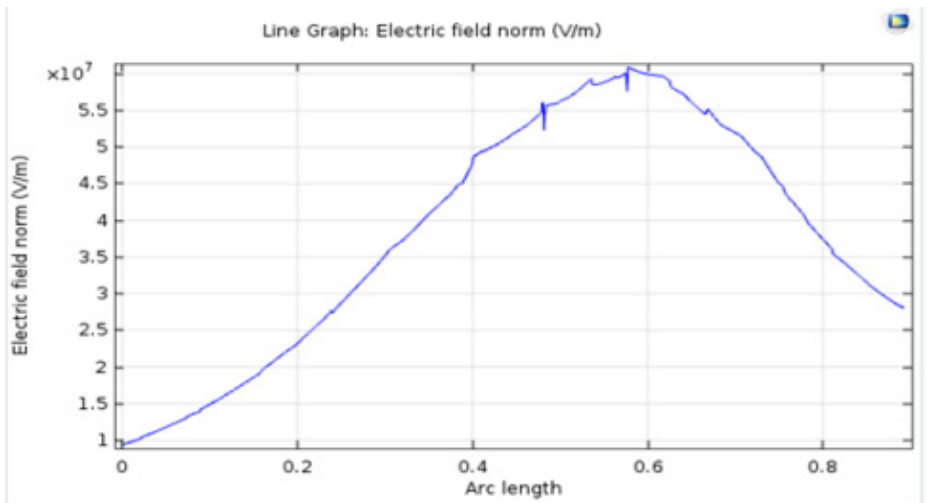

Figure 7: Electric field and electric potential on contour of disc insulator under contamination possession with COMSOL simulation approach

As depicted in above figure, the electric field gradient across the surface of insulators is grossly enhanced due to the deposition of pollutions which cause the surface flashover at relatively low electrical potential. 


\section{Results and discussions}

Table 1: Flashover voltage characteristics of porcelain insulators under different polluted condition

\begin{tabular}{|c|c|c|c|}
\hline \multirow{2}{*}{ Nature of Condition } & \multicolumn{3}{|c|}{ Breakdown Voltage $(\mathrm{kV})$} \\
\cline { 2 - 4 } & Pin Insulator & Disc Insulator & Shackle Insulator \\
\hline Room Atmosphere & 96 & 96 & 22 \\
\hline NaCl Contaminated & 36 & 44 & 14 \\
\hline $\begin{array}{c}\text { Miscellaneous indus- } \\
\text { try pollutants }\end{array}$ & 78 & 54 & 20 \\
\hline
\end{tabular}

The flashover voltage characteristics have been observed for different insulators for various physical conditions. Table 1 and Fig. 8 represent the details of breakdown voltage obtained for Pin, Disc and Shackle insulator at room atmosphere and polluted condition.

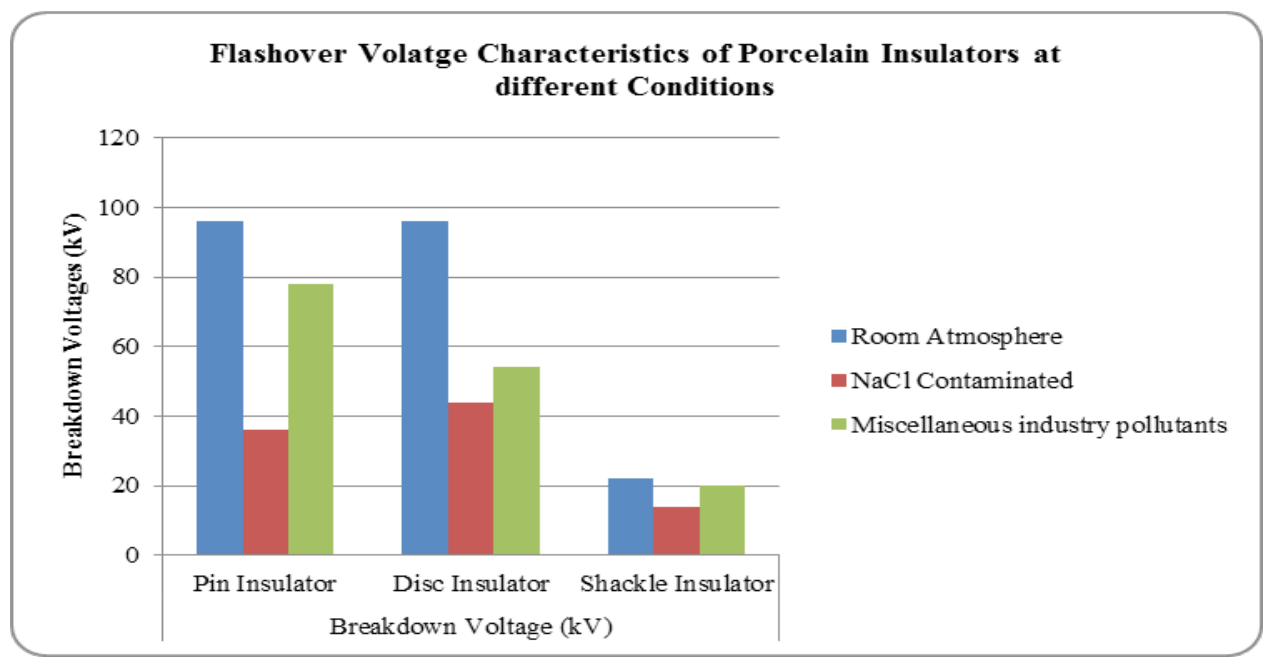

Figure 8: Flashover voltage characteristics of porcelain insulators under different contaminated condition

The results show that flashover voltage of insulators is found to be higher during dry condition as compared to polluted conditions. The reduction in flashover voltage under polluted condition is due to increase in surface conductivity and presence of preliminary ionizers.

As increased high voltage is applied across the insulators contaminated by the pollutions, the electric field across its surface is grossly enhanced due to increase in surface conductivity. The increased conductivity allows more number of electron and positive charge injection over the surface of insulators and hence makes ionization faster at relatively low voltage. When the field across the insulator exceeds the critical value, the discharge activity starts appearing and pro- 
gressively it covers the entire surface of insulators.

\section{Conclusion}

The investigation result shows that breakdown voltages, performance and life cycles drastically affected by the dust particles, $\mathrm{NaCl}$ Contamination deposition as well as some miscellaneous manufacturing industries polluted substances like lime stone, cement particles and other pollutants.

- For fair and proper design of outdoor insulation accurate knowledge of pollutant locations take into the consideration so it's very important to carry out proper site investigation for incorporating of such insulators.

- By doing rigorous analysis of different physical and chemical contamination layers on surface of insulators we can check the flashover performance of insulators.

- Soluble contamination such as $\mathrm{NaCl}$ particle is having significant effect on flashover voltage.

- Insoluble contamination such as cement and other particle are not having significant effect but they aid the impediment of ionic movement.

- For multi contaminant deposition or mixed polluted condition anions and cations are having again significant effect on insulators and eventually all these pollutants decrease the life cycle of insulators.

\section{References}

[1] Aulia, L. M. Padang, F. David, E. P. Waldy and H. Hazmi, "Leakage current analysis on $20 \mathrm{kV}$ suspension porcelain insulator contaminated by salt moisture and cement dust in padang area", IEEE International Conference on Properties and applications of Dielectric Materials, Bali, Indonesia, pp. 384-387, 2006.
[2] C. Engelbrecht et al., "Pollution tests for coastal conditions on an $800 \mathrm{kv}$ composite bushings," IEEE Transactions on Power delivery, vol. 18, no. 3, pp. 953958, 2003.

[3] G. G. Karady, "Flashover mechanism of Non-Ceramic Insulators," IEEE Transactions on Dielectric and electrical insulation, vol. 6, pp. 718-723, 1999.

[4] H. Homma et al., "Determination of long term performance of polymeric insulators for distribution lines by salt fog method", Annual conference on Electrical insulation and dielectric phenomena, pp. 401-404, 2006.

[5] H. Wang and G. Liu, "Study on insulator natural contamination trend under different physiognomies of local area," IEEE International Symposium on Electrical Insulation, Vancouver, BC, Canada, pp. 89-93, 2008.

[6] H. Ye, et al., "Contamination accumulation and withstand voltage characteristics of various types of Insulators", IEEE 7th Internetional Conference on Properties and Applications of Dielectric materials, Nagoya, Japan, pp.10191023, 2003.

[7] IEC 60060-1, "High-voltage test techniques - General definitions and test requirements", 2010.

[8] IEC 61109, "Composite insulators for a.c. overhead lines with a nominal voltage greater than 1000 V- Definitions, test methods and acceptance criteria," 1992 .

[9] J. Sun et al., "Influence of pollution distribution on insulator surface on flashover characteristics," IEEE Transactions on Dielectric and electrical insulation, vol. 21, pp.1637-1646, 2014.

[10] J. Sun et. al., "Pollution accumulation on rail insulator in high speed aerosol," IEEE Transactions on Dielectric and electrical insulation, vol. 20, pp.731- 738, 2013.

[11] K. Izumi and K. Kadotani, "Applica- 
tions of polymeric outdoor insulation in japan," IEEE Transactions on Dielectric and electrical insulation, vol. 222, no. 6, pp. 595-604, 1999.

[12] M. A. R. M. Fernando and S. M. Gubhanski, "Leakage Current Patterns on Contaminated Polymeric Surfaces," IEEE Transactions on Dielectric and electrical insulation, vol. 6, pp. 688-694, 1999.

[13] R. Barsch, H. Jahn and J. Lambrecht, "Test methods for polymeric insulating materials for outdoor hv insulation," IEEE Transactions on Dielectric and electrical insulation, vol. 6, pp. 668-674, 1999.

[14] R. Hernandez, I. Ramirez and G. Montoya, "Evaluation of $23 \mathrm{kv}$ insulator profiles with different pollution levels", 19-22 Sept., IEEE Internetional Symposium on electrical Insulation, Indianapolis, IN, USA, pp. 304-307, 2004.

[15] S. Chandrasekar and C. Kalaivanan, "Investigation on leakage current and phase angle characteristics of porcelain and polymeric insulator under contaminated conditions", IEEE Transactions on Dielectric and electrical insulation, vol.16, pp. 574-583, 2009.

[16] T. Kikuhi, S. Nishimura, M. Nagao, KIzumi, Y. Kubota, and M. Sakata, "Survey on the use of non-ceramic composite insulators," IEEE Transactions on Dielectric and electrical insulation, vol. 6, pp. 548-556, 1999.

[17] Z. Zhang, D. Zhang and X.Jiang, "Study on natural contamination performance of typical types of insulators," IEEE Transactions on Dielectrics and electrical insulation, vol. 21, pp. 1901- 1909, 2014. 